\title{
A Cognitive Study of "Happiness" Metaphors in English and Chinese Idioms
}

\author{
Peilei Chen \\ Foreign Language School, Henan University of Technology \\ Zhengzhou 450052, Henan, China \\ E-mail: englishplay@sina.com
}

\begin{abstract}
Happiness is one of the basic human emotions. This paper takes the metaphorical expressions of "happiness" in English and Chinese idioms as the objects of research. The effort is made to find the differences and similarities between English and Chinese metaphorical systems of emotional concepts and the causes of these differences and similarities so as to help people further understand the nature of emotional metaphors.
\end{abstract}

Keywords: Cognition, Happiness, Metaphor, English, Chinese, Idioms

The contemporary metaphor theory in cognitive linguistics regards metaphors as playing an important role in the conceptualizing process of emotions (Lakoff \& Johnson, 1980: 15-21); and metaphors of emotions in the language are most typical examples to show how abstract concepts are structured by more concrete concepts metaphorically, for emotions are highly unstructured concepts. Idioms of "Happiness" in English and Chinese are good examples to prove that there are same metaphorical concepts of emotions in English and Chinese languages, and on the other hand, metaphors are greatly nation-specific and culture-loaded.

\section{Similarities of "Happiness" Metaphors in English and Chinese Idioms}

Happiness is one of the basic human emotions. According to the explanation of general psychology, happiness is the pleasure and comfort felt by individuals when the objectives they long for have been achieved and the stress been released. In addition, when people's wishes are fulfilled in unexpected time and occasions, it will also bring them the experience of happiness.

\subsection{Happiness is Up}

According to the researches by cognitive linguists Lakoff \& Johnson (1980) and Kovecses (1986), in English the metaphors expressing "happiness" are mostly related to space and orientation: the erect posture of body is used to express happiness, thus the conceptual metaphor HAPPY IS UP is formed (Lakoff \& Johnson, 1980). Many such expressions can be found in English idioms:

with a light heart, (to get one's) tail up, to leap / jump out of one's skin, to throw

up one's cap/to throw one's cap in the air, to walk/dance on air, in the seventh heaven.

In the above examples the words "up", "leap", "jump", "heaven" and "light" are all related to UP and used to express happiness. There are many similar examples in Chinese idioms:

兴致勃勃 兴高采烈 兴致盎然 意气风发

When we use these words to express happiness, we don't realize there're metaphors yet. Such forms of expression are bases on the body experience of human beings: erect posture is often accompanied by positive emotions. In the development of human cognition and languages, it's easier to perceive the concept of space, which came into being earlier. So some words initially used for space concepts were later adopted to metaphorize such abstract concepts as time and emotions. Because of the similarity in human cognitive development of space concept and the same physical experience of human beings, there is the metaphorical concept HAPPY IS UP in both English and Chinese.

\subsection{Happiness is Fluid in a Container}

In English and Chinese idioms, there's another common conceptual metaphor for happiness: HAPPINESS IS FLUID IN A CONTAINER. We can find this conceptual metaphor in English idioms:

to burst/split one's sides (with laughing), to burst into laughter 
In Chinese there are also some examples of this kind:

\section{满怀喜悦 热情洋溢 满心欢喜 心满意足}

From the above examples, we can see both English and Chinese view the human body as a container. Emotions, as is well known, are abstract concepts. The subject of emotional experience--human body, is a container with inside and outside divided by the skin. When people are happy and excited, their blood circulation speeds up and the container--human body, becomes full. When the emotion gets stronger it will overflow; and when it overwhelms, it will burst out. So there is the conceptual metaphor HAPPINESS IS FLUID IN A CONTAINER in both languages.

\subsection{Happiness is the Physiology Reaction of Happiness}

HAPPINESS IS THE PHYSIOLOGY REACTION OF HAPPINESS. Both English and Chinese people have some body actions to express happiness. In English there are: kick up their heels, grin from ear to ear etc. In Chinese there are:欢呼雀跃手舞足蹈,喜笑颜开 etc.

In both the languages, the most typical behavior applied to convey happiness is laughing (smiling), e.g. to have a good laugh, to burst into laughter, Homeric laughter, to roar with laughter, to be all smiles, 忍俊不禁,笑容可掬, 笑语喧哗,喜笑颜开. Besides, both English and Chinese realize that happiness is something felt by heart so they cheer the cockles of one's heart (do one's heart good), with a light heart, or 心花怒放，心旷神怡.

The existence of these common metaphors is because of the same body structures and physical characteristics of human beings. So English and Chinese people have the same body experience and both use body actions to express the most basic emotion "happiness".

\section{Differences between "Happiness" Metaphors in English and Chinese Idioms}

Due to the different cultures of English and Chinese people, the metaphorical concepts of happiness in these two languages have respective characteristics.

\subsection{Being Happy is Being Off the Ground}

In English, there is the conceptual metaphor BEING HAPPY IS BEING OFF THE GROUND. The following are some examples:

be six feet off the ground, in the clouds, walk on air

While, in Chinese culture and language, where modesty and sedation are considered to be virtue, "being off the ground" is the symbol of being proud and complacent. So in Chinese there are such expressions: 飘飘然,云里雾 里,云山雾罩.

The above differences in metaphorical expressions come from different value concepts of English and Chinese people. Because "the language itself is a kind of cultural force and cultural mode, people acquire this language from childhood, and the cultural symbols including all the cultural concepts, values, norms and customs are molded into their own thought and behavior."(Dai Mingzhao, 1996: 26), the values of different nations are inevitably reflected in their languages. The Chinese people are relatively reserved and tend to suppress their feelings. So in Chinese "being off the ground" is considered to be the symbol of proud and self-satisfaction. On the contrary, English people are rather frank and direct in manner, so there's the conceptual metaphor HAPPINESS IS BEING OFF THE GROUND in English.

\subsection{Happiness is Reactions in Eyes and Brows}

Apart from the identical ones discussed above, Chinese idioms apply much more concrete and trivial actions to convey happiness like raising eyebrows(扬眉吐气), fluttering eyebrows(眉飞色舞), parting eyebrows(眉开眼 笑), relaxing eyes(展眼舒眉), smiling in eyes(眉开眼笑), clapping hands(拍手称快), roaring(欢声雷动), singing and dancing(载歌载舞) and so on.

In English idioms conveying happiness, the image of eyes rarely appears. But there are some idiomatic expressions which reflect the conceptual metaphor HAPPINESS IS REACTIONS IN EYES:

His eyes were shining.

Her eyes were sparkling like diamonds.

Amusement gleamed in his eyes.

But in Chinese idioms, happiness is not only reactions in eyes, but in brows. In Chinese the conceptual metaphor of happiness is HAPPINESS IS REAC T IONS IN 
EYES AND BROWS. Here are some examples:眉开眼笑,喜上眉梢,喜眉笑眼. As we can see, to express happiness with eyes, in English the emphasis is laid on light in eyes, while in Chinese the shape of eyes is stressed.

In Chinese, brows are so active in conveying emotions and the idiom 眉目传情 itself verifies this point. Apart from happiness discussed already, eyebrows in Chinese idioms may convey sadness(眉头紧锁, 愁眉苦脸), anger(柳眉倒坚), obedience(低眉顺眼,低眉折腰), flirtatiousness(眉来眼去), and urgency(燃眉之急,迫在眉 睫).

\subsection{Happiness is the Flower in one's Heart}

Lastly, in Chinese there's a minor conceptual metaphor HAPPINESS IS THE FLOWER IN ONE'S HEART. Heart is compared to a flower blooming in profusion, which is a fairly vivid picture familiar to everyone. This metaphor comes from Chinese traditional culture in which blooming flowers are the symbol of happiness, for example:乐开了花,心花怒放,花好月圆.While, in English there are neither such cultural symbols nor such metaphorical expressions.

\section{A Brief Summary}

\subsection{The Universality of "Happiness" Metaphors in Idioms}

Orientational metaphor maps the orientational concepts in the source domain onto the abstract target domain with spatial schemas and inner-logic preserved. Similar experiential and physical grounding of humans leads to the resemblance of orientational metaphors. Erect posture stands for a positive emotional state. Because of this common physical basis of human beings, the orientational metaphors HAPPINESS IS UP are present in both English and Chinese idioms.

People have strong kinesthetic experiences of bodily containment. We are physical beings, bounded and set off from the rest of the world by the surface of our skins, and we experience the rest of the world as outside us. So both English and Chinese people view the human body as a container, with a bounding surface and an in-out orientation. When people are emotional, the container-human body becomes full. When the emotion gets stronger it will overflow; and when it overwhelms, it will burst out. So there are the container metaphors HAPPINESS IS FLUID IN A CONTAINER in English and Chinese idioms.

\subsection{The Cultural Specificity of "Happiness" Metaphors in Idioms}

Because of the difference in cultures, happiness metaphors in English and Chinese have respective characteristics. The difference lies in the two peoples' geographic environments, personalities, value, concepts, thinking modes and views of the world, which are reflected in their idioms conveying happiness.

English people are rather frank and direct in manner. To express their emotions, they often apply obvious movements of the whole body or of the four limbs that can be seen from a long distance away. From the different parts of human body or movements applied we may reach a conclusion that English idioms have a tendency towards outwardness. English speakers do not think the liver, the gall and the intestines have anything to do with human's psychology. In any possible cases in which the Chinese might think of other internal parts, they just turn to the heart.

In Chinese traditional culture, modesty, sedation, gentleness and obedience have been regarded as great virtues for thousands of years. So compared with English people, the Chinese people are relatively reserved and tend to suppress their feelings. Much more attention is paid to concrete and inwardness by Chinese people, who tend to express their happiness with movements of rather smaller parts of the body such as eyebrows, inner organs, and even the invisible soul and vital energy. Of course, we also have the actions of beating breast and stamping, but they are not of dominant tendency to be discussed. The Chinese always relate the changes of human moods to the five internal organs, i.e. heart, liver, spleen, lungs and kidneys, which have their deep resources from traditional Chinese medical science. Vocal organs are also involved in both English and Chinese idioms, but they appear in different directions.

\subsection{Conclusion}

Because the generalities lying in the structure of thought and physiology that English and Chinese both share, English and Chinese people have similar knowledge about idioms, and therefore there are many similarities in English and Chinese idioms. But due to the different cultures and types of languages of the two countries, it results in many differences in the form and semantics of the two languages' idioms. The analysis can help people further understand the nature of emotional metaphors. 


\section{References}

Dai, Mingzhao. (1996). An Introduction to Cultural Linguistics. Beijing: Language and Literature Press.

Kovecses, Zoltan. (1986). Metaphors of Anger, Pride, and Love: A Lexical Approach to the Structure of Concepts. Amsterdam/Philadelphia: John Benjamin's Publishing Company.

Lakoff, G \& M. (1980). Johnson. Metaphors We Live By. Chicago: University of Chicago Press.

Lan, Chun. (2005). A Study of Cognitive Linguistics and Metaphor. Beijing: Foreign Language Teaching and Research Press.

Ning, Yu. (1998). The Contemporary Theory of Metaphor: A Perspective from Chinese. Amsterdam/Philadelphia: John Benjamin's Publishing Company.

Ye, Yiqian. (1991). General Psychology. Shanghai: East China Normal University Press.

Zhao, Yanfang. (2001). An Introduction to Cognitive Linguistics. Shanghai: Shanghai Foreign Language Education Press. 